Session 2154

\title{
The Maryland Industrial Partnerships: A Model for Academic- Industrial Technology Commercialization
}

\author{
Martha Connolly, David Barbe, Peter Hudson, Judith Mays, \\ Herbert Rabin, Eric Schurr \\ Maryland Technology Enterprise Institute \\ University of Maryland, College Park
}

\section{Introduction}

The Maryland Industrial Partnerships (MIPS) Program was established in 1987 to promote commercialization of new technologies, and to create partnerships between the University of System of Maryland (USM) and Maryland businesses. USM comprises eleven universities and two research institutions. MIPS accelerates the commercialization of new technology by jointly funding commercially directed collaborative research and development projects between USM faculty and company researchers. Faculty, postdoctoral fellows and graduate students have the opportunity to perform research that directly leads to commercialization of new products. Companies are able to access expert university faculty and state of the art facilities to conduct cost effective research and development. They also benefit from access to a vibrant student labor pool. MIPS projects have covered a wide range of technologies in engineering, computer, physical and life sciences. Since 1987, MIPS has provided matching funds for more than 445 projects worth a total value of $\$ 120$ million in R\&D expenditures. MIPS-supported projects have increased product sales, provided jobs to the region, and infused state-ofthe-art technology into the global marketplace. Commercial products aided by MIPS projects include MedImmune's Synagis ${ }^{\circledR}$ for infant respiratory disease, Black and Decker's Bullet Speed Tip Masonry Drill Bit, Hughes Network Systems' DIRECWAY satellite internet product, Martek Biosciences' Formulaid ${ }^{\circledR}$ infant formula additive, and Quantum Sail Design Group's off-wind sails for performance yachts. MIPS is an effective technology commercialization program using a well established and successful model for university-industrial collaborations.

\section{Program Mission}

The Maryland Industrial Partnerships (MIPS) Program is a technology transfer and economic development program that promotes the development and commercialization of products and processes through industry/university research partnerships. Through MIPS, University faculty and graduate students conduct research projects for Maryland companies. Two features that distinguish this program from other research programs are that (1) MIPS proposals are evaluated not only on technical merit, but most importantly on potential for economic benefit and (2) projects are jointly funded by the companies 
and by MIPS. The mission of MIPS is three-fold: (1) to provide a well-understood mechanism for Maryland companies to gain access to knowledge and expertise of faculty and graduate students and to facilities associated with the extensive research base in engineering, computer science, physical sciences and life sciences; (2) to provide faculty and students with opportunities to transfer technology through product-oriented projects for Maryland companies; and (3) to enhance the economy of Maryland by helping Maryland companies to be more competitive and thus to create jobs.

\section{Program History}

MIPS is part of a larger statewide technology development effort at the University of Maryland, College Park begun in 1984 with the establishment of the Engineering Research Center (ERC) as a unit of the A. James Clark School of Engineering. This center is now known as the Maryland Technology Enterprise Institute (MTECH). In 1984, the ERC began its activities with the Technology Extension Service, a program to provide direct technical assistance in solving manufacturing problems, and the Technology Advancement Program, an incubator for technology-oriented startups. In 1987, the ERC added the Maryland Industrial Partnerships (MIPS) program to its technology development programs to enhance the competitiveness of Maryland businesses by providing funding for joint industry/academic research and development projects. Funding for the program came as a specific allocation from the University of Maryland's budget for technology and economic development. Over the next sixteen years, the MIPS program evolved to be a major factor in the development of products resulting from academic-industrial linkages.

\section{Program Description}

The MIPS program subsidizes technology commercialization by jointly funding innovative, collaborative R\&D projects between Maryland companies and University System of Maryland faculty. Both MIPS and company funds go towards university project costs. Those projects which are competitively assessed to be of high technical merit and of commercial relevance are conducted by USM faculty in conjunction with company researchers. Companies leverage their R\&D funding and gain access to faculty expertise, while faculty can obtain funding to engage in commercially-relevant research. MIPS funding comes through the budget of the University of Maryland, College Park.

The University System of Maryland is composed of 13 member institutions. Any faculty member within the USM can apply for MIPS funding. All Maryland companies are eligible to participate. Companies and faculty are matched through active partnering efforts by the MIPS staff and through pre-existing relationships. If faculty and companies do not already have relationships, MIPS staff will help to find matches for faculty who have proposed projects but are not aware of appropriate company partners, and conversely, MIPS will find faculty partners for companies that have proposed projects but are not aware of suitable faculty. This is done by asking companies to outline what product issues need to be addressed and what expertise and/or capabilities they would need in order to advance the product development. These requests are used 
by MIPS staff to identify faculty, either through direct faculty or by contact through department chairs or other UM faculty. In this regard it is advantageous that the MIPS staff is part of the University and is aware of faculty expertise. The result is that companies express their needs, and through joint efforts, a UM system faculty member is identified as a partner. For consideration, proposals must be co-authored by a faculty member and by a company representative. Proposals must be technological in and are rigorously reviewed based on both technical and economic merit.

\section{Proposal Mechanisms}

Applications are accepted two times per year, and are subject to a rigorous evaluation process consisting of reviews of both technical merit and economic potential. Technical reviewers are experts in the technical field of interest, and typically come from academic and government laboratories. These reviewers provide a peer review with feedback on technical issues including feasibility, adequacy of experimental approach, appropriateness of the budget and facilities. Economic evaluators from the regional community include business school faculty, incubator managers, venture capitalists, economic development professionals and service providers (bankers, accountants, attorneys, business consultants, and executive search professionals). Economic evaluators are asked to rate the economic development potential of the project (likelihood of commercial success, new job growth, and potential for revenue). For each proposal, a discussion is conducted with the economic reviewers and a final economic evaluation score is determined. The economic and technical evaluations are presented to a separate evaluation board which determines the final ranking, and awards are made according to that ranking. Both technical and economic potential reviews are accomplished within two months of the application submissions, so that a rapid turn around time results. Funding recommendations and awards are announced soon thereafter, leading to signed contracts and project initiation 12-14 weeks after application submission.

Companies must provide matching funds based on their size. There are four categories of company size: start-ups in business less than four years (fewer than 14 employees), small companies (fewer than 100 employees), medium-sized companies (100-1000 employees), and large companies (more than 1000 employees). Company cash contributions to projects must be at least $10,35,50$ or $75 \%$ for start-up, small, medium and large companies, respectively.

If a proposal is ranked high enough to be funded, the combination of company and MIPS funding is deposited in a University sponsored research account. The funding is available to the faculty principal investigator and is administered through the UM institution's sponsored research office. Most projects are conducted as collaborative efforts between faculty and company personnel; accordingly, frequent progress meetings are held to ensure that project objectives are met.

The work statement is executed by the PI with graduate students and post-doctoral fellows participating, as appropriate. Many past projects have been the subject of theses 
and publications, and in some cases, graduating students involved in projects have been hired by the sponsoring companies.

If intellectual property is generated during the conduct of the project, it is either owned by the University (if disclosed solely by the principal investigator), or jointly owned by the company and the university if the IP is jointly disclosed. The university offices of technology transfer handle the patent prosecution and licensing of the intellectual property according to their standard policies. In the event that a licensable technology is developed, the company has the first right of refusal for an exclusive license. Faculty and

graduate students are free to publish in the usual manner, with a possible delay of six to twelve months.

Measures of success are monitored for up to five years following a project award. Companies are asked to provide data on product commercialization and product sales, job creation, export revenue, and other relevant data.

\section{Program Statistics}

Historically, MIPS funds have been leveraged by a 5:1 ratio (total project value to MIPS funds). As shown in Table 1, MIPS funding for R\&D projects has been more than $\$ 23$ million and company matching funds have exceeded $\$ 96$ million. Thus, every MIPS dollar results in five dollars being spent for R\&D in furtherance of Maryland economic development. At the same time, MIPS has brought extensive research funding into the University System of Maryland, contributing to the University research mission.

Table 1. Economic Value of MIPS Projects

\begin{tabular}{|lr|}
\hline MIPS funds & $\$ 23,230,890$ \\
\hline Company matching funds & $\$ 96,408,506$ \\
\hline Total MIPS projects value & $\$ 119,639,396$ \\
\hline Leverage of MIPS funding & $5.1: 1$ \\
\hline
\end{tabular}

Table 2 provides data associated with the number of projects, distribution of projects according to company size, and the number of faculty that have participated in MIPS projects.

\section{Biotech and Homeland Security Projects}

Maryland is a state with a strong biotechnology base, and accordingly a significant portion of the MIPS projects have been conducted with companies engaged in research and development in the broad area of biotechnology. Of the 445 projects conducted since 1987, one-third have been biotech-related. Note that Biotechnology as used here includes the broad categories of Biotechnology/Genetic Engineering, Chemical Engineering/Chemistry, Food Processing and Agriculture/Poultry Science. 
Since 9/11, MIPS has funded a variety of projects related directly to homeland security applications, with a total project value of $\$ 912,082$. Project areas include biodefense and biohazard detection, chemical sensors, fiber optic communications, unmanned autonomous vehicles, and enhanced military communications.

\section{Table 2. MIPS Project Statistics}

\section{MIPS Projects}

\begin{tabular}{|l|l|}
\hline Number of projects & 445 \\
\hline Number of participating companies & 300 \\
\hline Companies with multiple projects & 70 \\
\hline Percentage of projects with large- and medium-sized companies & $34 \%$ \\
\hline Percentage of projects with small companies & $30 \%$ \\
\hline Percentage of projects with start-up companies & $36 \%$ \\
\hline Number of participating faculty & 256 \\
\hline
\end{tabular}

\section{MIPS Product Examples}

MIPS projects have a record of success having contributed to the development of MedImmune's Synagis, Martek's Formlulaid, Black \& Decker's Bullet Speed Tip Masonry Drill Bits, and Hughes Network Systems' DIRECWAY broadband satellite service, and many other products, and several are highlighted below.

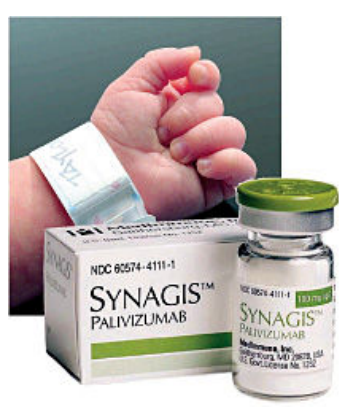

\section{Synagis, produced by MedImmune (Gaithersburg, MD)}

MIPS jointly funded six different research projects with MedImmune, including three directly related to Synagis ${ }^{\circledR}$ (http://www.medimmune.com/products/synagis/index.asp) since 1996. MIPS "helped in [the] structural testing of Synagis ${ }^{\circledR}$ lots," said MedImmune scientist Dr. John Hope in a post-project report. "The process for which the MIPS grant assisted in development of is still being used at MedImmune for testing Synagis ${ }^{\circledR}$ and related glycoproteins.” Synagis ${ }^{\circledR}$ prevents serious lower respiratory tract disease caused by respiratory syncytial virus in pediatric patients at high risk of RSV disease. RSV is prominent in the Northern Hemisphere from October through May. MedImmune has the 6th-highest revenue of any biotech company in the Americas (\$848 million), and ranks as the $3^{\text {rd }}$-highest biotech company in terms of market cap/revenue ratio, according to the "2003 Ernst \& Young Americas Biotechnology Report." Total sales for Synagis ${ }^{\circledR}$ since 2000 exceed $\$ 1.6$ billion; Global sales for Synagis ${ }^{\circledR}$ in 2002 were $\$ 668$ million; through 
the first three quarters of 2003, sales are up 27 percent, to $\$ 481$ million. MedImmune employs 1,700 people, and has operations in Gaithersburg (headquarters) and Frederick, as well as in Pennsylvania, California, the United Kingdom and the Netherlands. Approximately 690 people are employed locally.

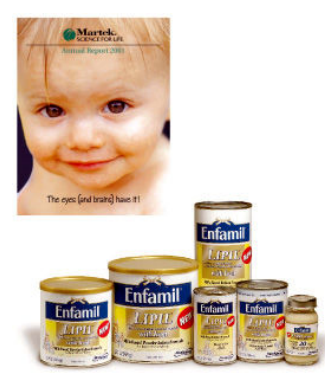

\section{Formulaid ${ }^{\circledR}$, produced by Martek (Columbia, MD)}

Martek's product, Formulaid $\AA$

(http://www.martekbio.com/Nutritional_Products/Introduction.asp), is a patented blending of nutritional oils (docosahexaenoic acid (DHA) and arachidonic acid (ARA), produced from microalgae, largely licensed to infant formula manufacturers. Formulaid®, consists of essential fatty acids that are critical to the development of the eyes and central nervous system in newborns. MIPS helped Martek evaluate the best procedures for maximizing DHA yield from the company's microalgae proprietary process. Access to MTECH's Bioprocess Scale-Up Facility was critical. According to Henry "Pete" Linsert, chairman of Martek, scaling up DHA and ARA "was a crucial step in making our infant formula additives feasible." Martek has license agreements with thirteen infant formula manufacturers representing more than two-thirds of the world's wholesale infant formula market. Formulas containing Martek's oils are now available in more than 60 countries worldwide, including the United Kingdom, Mexico, China, the United States and, most recently, Canada. In 2003, Nestle USA, part of Nestle S.A., introduced Nestle Good Start Supreme DHA \& ARA infant formula in the US. The new formula contains a blend of Martek's DHA and ARA oils. The oils have also been incorporated into Mead Johnson's successful Enfamil LIPIL product line. Martek's total revenues for FY 03 were $\$ 114.7$ million, an increase of $\$ 68.7$ million or $149 \%$ over FY 02 , primarily due to higher sales of nutritional products to the Company's infant formula licensees.

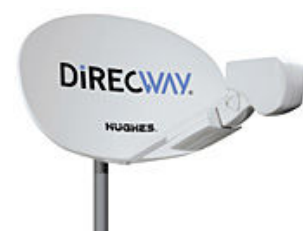

\section{DIRECWAY®, produced by Hughes Network Systems (Germantown, MD)}

DIRECWAY ${ }^{\circledR}$ broadband satellite network

(http://www.direcway.com/) is the world's leading broadband by satellite service, providing high-speed, IP-based connectivity to the large enterprise, small/medium enterprise, small office/home office, and rural markets. DIRECWAY® is now available around the globe through HNS directly and from authorized value-added resellers. HNS jointly developed DIRECWAY® with the University of Maryland, College Park's Dr. John Baras through several MIPS projects. The product was initially launched as DirecPC. More than 600,000 systems have been ordered or shipped to customers in 85 countries. HNS pioneered the development of high-speed satellite Internet access services, which it markets globally under the DIRECWAY ${ }^{\circledR}$ brand and is a major supplier of mobile satellite networks, including GSM-enabled portable handsets and Internet devices. As of September 30, 2003, the DIRECWAY ${ }^{\circledR}$ service had approximately 178,000 residential subscribers in North 
America - compared to 138,000 one year ago-representing an increase of approximately $29 \%$. As part of its broadband strategy, HNS intends to launch the $\$ 1.8$ billion SPACEWAY system in North America in 2004, which will consist of three inorbit satellites built by Boeing Satellite Systems, Inc., and ground systems provided by HNS. The SPACEWAY platform will enable HNS to offer high-speed "bandwidth-ondemand," providing customers with the ability to transmit and receive via satellite any combination of data, video, audio, and multimedia while paying only for the amount of bandwidth they use. Hughes Network Systems, a wholly owned subsidiary of Hughes Electronic Corporation, has more than 25 facilities and sales offices around the world, and employs over 5,000 (including joint ventures) people in engineering, operations, marketing, sales and support. It operates manufacturing facilities in Maryland, Milton Keynes, UK, and Tijuana, Mexico. Affiliate companies in India include Hughes Software Systems, a publicly traded software development subsidiary, and Hughes Escorts Communications Ltd. (HECL), a provider of broadband satellite communications services.

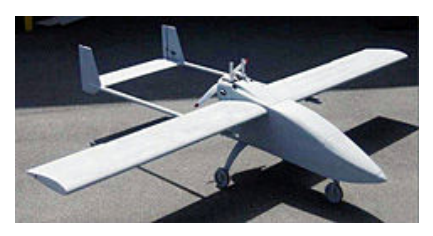

\section{MAKO UAV, produced by Navmar Applied Sciences Corporation (Lexington Park, MD)}

The MAKO unmanned autonomous vehicle (UAV) is a revolutionary aircraft, related to the Predator UAV used by the U.S. military during missions in Afghanistan. The MAKO is light, inexpensive, can travel far distances and can carry substantial payloads, and importantly - is expendable. With a wingspan of twelve feet eight inches and weighing just 75 pounds, the MAKO can fly for five hours, or 350 miles, on one five-gallon tank of gasoline. The MAKO can suit many missions, from reconnaissance to payload release. Through MIPS, UM personnel evaluated the aero dynamics of the aircraft, flight control system, propulsion analysis, wing loading design analysis, and glide ratios. UM faculty also helped select a design for the final vehicle. MIPS' project with Navmar (http://www.navmar.com/ ) also gave the company access to lab space and the Glenn L. Martin Wind Tunnel. Navmar is manufacturing approximately one MAKO per week, with 26 already shipped to the U.S. military. Navmar's MIPS project, which played a key role in developing the MAKO, enabled the company to award $\$ 10$ million in subcontracts to nine Maryland companies, including Brandebury Tool (Gaithersburg), BAE (Easton), API (Baltimore), Sullivan Products (Baltimore), Ship Point (Patuxent River), Neany Inc. (Patuxent River), Rugged (Patuxent River), Titan (Patuxent River), and Compass Systems (Patuxent River). The company hired 12 new employees, and subsequently opened three facilities in Maryland (Lexington Park, New Carrollton, and Chestertown). Navmar then launched two new spin off companies - Neany Inc. and Rugged, both in the Patuxent River area.

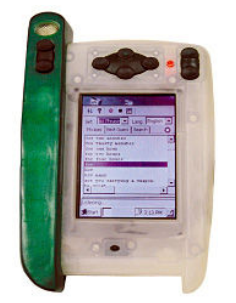

\section{Phraselator, produced by Applied Data Systems (Columbia, MD)}

Applied Data Systems is a leading developer of application-ready RISCbased embedded systems. Phraselator Translation System (http://www.phraselator.com/) is a PDA-sized device developed by ADS 
and used by military personnel in the extreme temperatures of Afghanistan to translate English into the four languages spoken there, at a 98 percent accuracy rate and in near real-time. The ADS research with UM focused on validating extended temperature ranges for industrial embedded systems applications. The results were incorporated into the new speech translation device, which can perform in the harshest heat and cold. ADS received Washington Technology's prestigious "2003 Fast 50 Government Contractors" award for the Washington DC-Baltimore region. Rankings are based on the percentage of government sector business growth. Applied Data Systems was recognized as the $30^{\text {th }}$ fastest growing company in the Fast 50. The company reported $\$ 8.9$ million in revenue for 2002 , as well as a $66.8 \%$ growth rate.

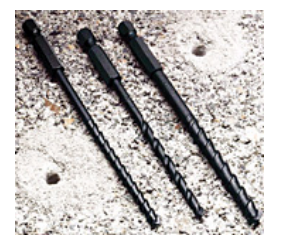

\section{Bullet Speed Tip Masonry Drill Bit, produced by Black \& Decker (Towson, MD)}

Black \& Decker is a leading global manufacturer and marketer of power tools and accessories, hardware and home improvement products, and technology- based fastening systems. Black \& Decker's 3 MIPS projects transformed the design process from an art form into a scientific inquiry which developed the relative parameters for drilling. This technology is now used in a line of 29 drill bits

(http://www.blackanddecker.com/productguide/AccessorySelection.aspx?PHID=774\&R $\underline{\mathrm{HID}}=805$ ). Drills can now function up to two times faster than using competitive bits, and can drill up to six times more holes per battery charge with a cordless drill. Black \& Decker's Power Tools and Accessories division accounted for $\$ 3.1$ billion in sales for 2002 , nearly 71 percent of the company's total sales for that year.

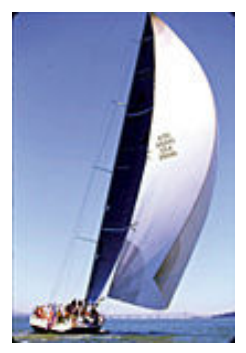

\section{World-class off-wind sails, Quantum Sail Design Group (Annapolis, MD)}

Quantum Sail Design Group designs, engineers, and manufactures sails for racers and cruisers who demand the highest levels of quality and performance. The designs developed under the MIPS program are used in all of Quantum's off-wind sail products (http://www.quantumsails.com/products/pline.asp?PLID=1 ). Quantum and UM developed the first U.S.-based wind tunnel testing facilities for downwind sails with the University of Maryland's Glenn L. Martin Wind Tunnel. Sails employing technology developed under the MIPS program were used in the Zephyrus V, which won "first to finish" honors in the $12^{\text {th }}$ Biennial West Marine Pacific Cup. Founded in 1996, Quantum is now the No. 2 sail maker in the world, with more than 54 lofts (design and manufacturing facilities) throughout the U.S., Australia, Canada, the Caribbean, Europe, the Pacific Rim, South Africa, and South America. In 2003, QSSD: opened a fifth loft in Australia, and opened Quantum South Asia operation in Malaysia. 


\section{Economic Impact}

Table 3 provides economic development data for four of the MIPS top project companies. These four companies have reported $\$ 1.73$ billion in sales dominated by MIPS-derived products.

Table 3. MIPS-Related Maryland Company Sales

\begin{tabular}{|l|l|l|}
\hline \multicolumn{2}{|c|}{ Company } & Sales \\
\hline MedImmune & Synagis & \$1.6 billion * \\
\hline Martek Biosciences & Formulaid & \$114 million ** \\
\hline Navmar Applied Sciences & MAKO UAV & \$10.1 million *** \\
\hline Applied Data Systems & Phraselator & $\$ 8.9$ million **** \\
\hline \multicolumn{2}{|l|}{ Total } & $\$ 1.73$ billion \\
\hline
\end{tabular}

$*$

$* *$

$* * *$

$* * * *$

Total reported sales of Synagis since 2000

Total sales, mainly nutritional product sales, for 2003

Includes Navy contract and 26 units shipped

Total Applied Data Systems sales for 2002

\section{Other Similar Programs}

Table 4 provides a view of selected state programs designed to support academicindustrial partnerships. Each program has unique goals and characteristics. All are directed towards development of technology driven university-business linkages. They differ in basic elements such as funding mechanisms, development of centers of excellence and, support for specific technology projects or initiatives. A major difference among these programs is the way they are administered. Most are, in fact, not operated by universities, but rather by state agencies, state-created non-profit organizations, or technology commissions. The MIPS program is among the small group administered by and funded through the university.

The program most similar to MIPS is the UC Discovery Grant Program, administered through the University of California. These two programs are university based programs, funded primarily by university (via state allocation) funds. Other programs are either funded through the state economic development agency (New York, Pennsylvania, Utah, and Wisconsin), run by technology commissions (New Jersey, Oklahoma) or independent organizations within the state (Georgia). These programs were established over the past 20 years; Maryland's is one of the older programs.

Major differences exist in how academic-industrial partnerships are implemented. Some states have chosen to fund centers of excellence (Oklahoma, New York, New Jersey), while others invest in specific development project linkages (Maryland, California, Pennsylvania and Wisconsin). 
Table 4. Selected State Programs Supporting Academic-Industrial Partnerships

\begin{tabular}{|c|c|c|c|c|}
\hline State & Program & Web Site & $\begin{array}{l}\text { Source of } \\
\text { funding }\end{array}$ & $\begin{array}{l}\text { Year } \\
\text { established }\end{array}$ \\
\hline California & $\begin{array}{l}\text { Discovery } \\
\text { Grants }\end{array}$ & $\begin{array}{l}\text { http://uc- } \\
\text { industry.berkeley.edu/welcome } \\
\text { asp }\end{array}$ & $\begin{array}{l}\text { State, } \\
\text { university, } \\
\text { industry }\end{array}$ & 1996 \\
\hline Georgia & $\begin{array}{l}\text { Georgia } \\
\text { Innovation } \\
\text { Grants }\end{array}$ & $\begin{array}{l}\text { http://www.gra.org/innovation } \\
\text { grants.asp }\end{array}$ & $\begin{array}{l}\text { State, } \\
\text { university, } \\
\text { industry }\end{array}$ & $\begin{array}{l}1990 \\
\text { (GRA) }\end{array}$ \\
\hline New Jersey & $\begin{array}{l}\text { Advanced } \\
\text { Technology } \\
\text { Centers }\end{array}$ & $\begin{array}{l}\text { http://www.state.nj.us/scitech/t } \\
\text { echentr_old.htm }\end{array}$ & $\begin{array}{l}\text { Technology } \\
\text { commission }\end{array}$ & 1985 \\
\hline New York & $\begin{array}{l}\text { Centers for } \\
\text { Advanced } \\
\text { Technology }\end{array}$ & $\begin{array}{l}\text { http://www.nystar.state.ny.us/c } \\
\text { ats.htm }\end{array}$ & State & 1983 \\
\hline Oklahoma & $\begin{array}{l}\text { Oklahoma } \\
\text { Applied } \\
\text { Research } \\
\text { Support }\end{array}$ & $\begin{array}{l}\text { http://www.ocast.state.ok.us/oa } \\
\text { rs.htm }\end{array}$ & $\begin{array}{l}\text { State technology } \\
\text { commission }\end{array}$ & 1987 \\
\hline$\overline{\mathrm{PA}}$ & $\begin{array}{l}\text { Ben } \\
\text { Franklin } \\
\text { Partnership } \\
\text { Program }\end{array}$ & http://www.benfranklin.org/ & State & 1983 \\
\hline Utah & $\begin{array}{l}\text { Centers of } \\
\text { Excellence } \\
\text { Program }\end{array}$ & $\begin{array}{l}\text { http://dced.utah.gov/techdev/in } \\
\text { dex.html }\end{array}$ & State & 1986 \\
\hline Wisconsin & $\begin{array}{l}\text { Technology } \\
\text { Developme } \\
\text { nt Fund }\end{array}$ & $\begin{array}{l}\text { http://www.commerce.state.wi. } \\
\text { us/MT/MT-FAX-0803.html }\end{array}$ & State & 1984 \\
\hline Maryland & $\begin{array}{l}\text { Maryland } \\
\text { Industrial } \\
\text { Partnerships }\end{array}$ & http://www.mips.umd.edu & University & 1987 \\
\hline
\end{tabular}

The common factor among all the states programs is the intent to capitalize on the technology base of universities to enhance economic development in the region. There is a general appreciation that the 'new economy' will be technology based, and that the universities will play a key role in that competitiveness for a given region.

\section{Establishing an Industrial Partnership Program}

For institutions interested in establishing a similar program, there are several important considerations. An institutional commitment to the process of technology transfer is important for sustainability. A strong commitment by the university as a research and 
development partner for industry is also essential. Metrics for successful commercialization should be carefully determined and promulgated to convey the impacts of this program to the university and companies, and other relevant constituencies such as executive and legislative officials. Being able to show measurable results of such programs is the key to its viability. Initial funding may be difficult to obtain, and local and state economic development organizations should be enlisted as partners. There are important considerations in the establishment of such programs, and lessons that we have learned are discussed below.

\section{Lessons Learned: Important factors to consider}

Keeping the university administration aware of the impact the program is having on the economy of the state or region is important because many states are looking to their major research universities to be economic engines.

Involvement in the community is important. Eliciting help from shareholders (economic development organizations, technology service professionals, industry advocacy groups, etc.) can be very productive. These multiplier groups can help in the proposal evaluation process, promote the program, and assist in finding technology partners matches between industrial and academic partners.

Good alliance management practices are critical. If a project appears to be going off track, taking appropriate steps to get it back on target as quickly as possible becomes critical to a successful project. Projects can get off track for various reasons such as lack of communication between the faculty PI and the company representative, deviation from the work statement, changes in direction of the company, changes in university or project personnel. Close monitoring of each project and early intervention if problems are sensed are necessary to preserve the alliance.

Good marketing of the program is also essential in order to obtain high quality proposals. This can be accomplished by close interaction with the faculty and potential corporate partners. Finding the right academic partner for the project can be time consuming, but is very important. Marketing, using electronic messages communicate with potential applicants about proposal requirements and deadlines is cost effective, and depends heavily on development of good marketing database capabilities.

A close interaction with the university technology transfer, legal and sponsored programs staff is helpful. Issues in intellectual property and contracts can be readily addressed when a good relationship exists between these administrative groups.

We realize that product success is difficult to predict. No particular research area or product type has emerged as dominant. Good product opportunities were found across a broad range of technologic disciplines. Some products (i.e. Synagis $\left.{ }^{\circledR}\right)$ have a longer development cycle than others, but even relatively straightforward products, as evidenced by the Black and Decker's Bullet Speed Tip drill bit, can be significantly improved using today's technologies. The best product successes come from the best faculty-company 
matching of capabilities and needs. Consideration of market size, time to market and competitiveness of the company in the proposal evaluation process are all beneficial to the success of projects.

Tracking the success of the projects is also important. It is often difficult to get companies to provide data for several years after a project is complete, however, this data can be very compelling in demonstrating success and attracting continued or enhanced funding for the program.

Establishment of a board of advisors for the program is also highly effective in obtaining independent advice on policies and procedures, especially since no set of operating principles and practices are static, and necessary improvements throughout the life of the program are critical.

\section{Summary}

The Maryland Industrial Partnerships Program has proven to be highly successful in establishing academic-industrial linkages. This program's 16-year history of promoting access to University System of Maryland faculty, expertise and facilities has resulted in enhanced product development, job creation, and increased competitiveness for Maryland's high technology industry.

Since 1987, the MIPS program has conducted 445 projects with participation of more than 250 faculty. The total investment by the MIPS program is $\$ 23.2$ million, which has been matched by company funds of $\$ 96.4$ million. This total R\&D investment of $\$ 120$ million has contributed to significant commercial product sales as noted in Table 3 . This program has positioned the University System of Maryland as a major contributor to the development of the high technology industry in Maryland.

\section{References}

Maryland Industrial Partnerships Program: http://www.mips.umd.edu California Discovery Grants Program: http://uc-industry.berkeley.edu/welcome.asp

Georgia Innovation Grants: http://www.gra.org/innovationgrants.asp

New Jersey Advanced Technology Centers: http://www.state.nj.us/scitech/techcntr_old.htm

New York Centers for Advanced Technology: http://www.nystar.state.ny.us/cats.htm

Oklahoma Applied Research Support: http://www.ocast.state.ok.us/oars.htm

Ben Franklin Partnership Program: http://www.benfranklin.org/

Utah Center for Excellence Program: http://dced.utah.gov/techdev/index.html

Wisconsin Technology Development Fund: http://www.commerce.state.wi.us/MT/MT-FAX-0803.html 
DAVID F. BARBE, Ph.D.

David F. Barbe is Executive Director of the Maryland Technology Enterprise Institute, Professor of Electrical and Computer Engineering and Faculty Director of the CEOs Program. He received B.S. ('62) and M.S. ('64) from West Virginia University and the Ph.D. ('69) from The Johns Hopkins University in Electrical Engineering. He is a Fellow of the IEEE. His publications deal with electronics technology and technology entrepreneurship.

MARTHA J. CONNOLLY, Ph.D.

Martha Connolly is the Director of the Maryland Industrial Partnerships (MIPS), a program of the Maryland Technology Enterprise Institute (MTECH). Dr. Connolly holds BS and MS degrees in Chemistry from Stevens Institute of Technology, and a Ph.D. in Biomedical Engineering from The Johns Hopkins University. A former faculty member at Johns Hopkins, and University of Maryland, Baltimore, she is the author of 36 publications in cardiovascular systems physiology and biomedical engineering.

\section{PETER W. HUDSON}

Peter has been the Associate Director of the Maryland Industrial Partnerships since 1996. His undergraduate and graduate degrees are from the University of Maryland. Prior to joining MIPS, Peter managed IR\&D projects at Westinghouse's Defense Group in Baltimore, MD. Since 1980 he has been adjunct faculty in Business and Management at the University of Maryland University College.

\section{JUDITH B. MAYS}

Judith Mays is Projects Manager of the Maryland Industrial Partnerships (MIPS), a program of the Maryland Technology Enterprise Institute (MTECH) at the University of Maryland. She has a bachelor's degree from the University of Pennsylvania and an M.B.A. from Marymount University. She has been an entrepreneur, an instructor in George Washington University's publications specialist program, and author of several articles in trade and consumer publications.

HERBERT RABIN, Ph.D.

Herbert Rabin is Associate Dean of the College of Engineering, Professor of Electrical and Computer Engineering, and the Director of the Maryland Technology Enterprise Institute at the University of Maryland, College Park. His degrees are in physics (BS University of Wisconsin, MS University of Illinois, and $\mathrm{PhD}$ University of Maryland), and he is a fellow of the American Physical Society, the Optical Society of America, the American Association for the Advancement of Science, and the American Institute of Aeronautics and Astronautics.

\section{ERIC SCHURR}

Eric Schurr is the Director of Communications for the Maryland Technology Enterprise Institute, a post he has held since 2001. His experience includes more than 250 published articles, for publications such as the Pittsburgh Post-Gazette, the Pittsburgh TribuneReview, the Washington Observer-Reporter, and the Valley News Dispatch. Eric earned his bachelor's degree in communications from John Carroll University. 